\title{
Associations Between Serum 25-Hydroxyvitamin $D$ Levels and Thyroid Function Parameters in Previously Healthy Children Aged 6 to 24 Months
}

This article was published in the following Dove Press journal: Risk Management and Healthcare Policy

\section{Yong Guo \\ Chun-Yan Wu \\ Yu-Hong Deng \\ Jie-Ling Wu}

Department of Children's Health Care, Guangdong Women and Children Hospital, Guangzhou Medical University, Guangzhou 5I I400, People's Republic of China
Correspondence: Jie-Ling Wu Department of Children's Health Care, Guangdong Women and Children

Hospital, Guangzhou Medical University, Guangzhou 5I I400, People's Republic of China

Tel +86203915I52I

Email jieling386I@I63.com
Purpose: Vitamin D deficiency has been linked to overt thyroid diseases. Data on the effects of vitamin D status on thyroid function in children are less examined. The goal of the present study was to explore the association between serum 25-hydroxyvitamin D [25(OH)D] levels and thyroid function parameters in early childhood.

Patients and Methods: This was a cross-sectional study involving record-linkage of children's data of routine health check-ups for promoting early childhood development at Guangdong Women and Children's Hospital; 2869 children aged 6-24 months were included from January 2015 to May 2017. Serum 25(OH)D, thyroid stimulating hormone (TSH), free triiodothyronine (FT3), and free thyroxine (FT4) levels were measured using the electrochemiluminescence immunoassay.

Results: The study population had a mean serum $25(\mathrm{OH}) \mathrm{D}$ level of $79.7 \pm 28.1 \mathrm{nmol} / \mathrm{L}$ and $12.5 \%$ vitamin D deficiency and $36.0 \%$ insufficiency rates. The rates of thyroid dysfunctions detected were $2.9 \%$ hypothyroidism, $4.2 \%$ subclinical hypothyroidism, $0.9 \%$ hyperthyroidism, and $1.7 \%$ subclinical hyperthyroidism among the previously healthy children aged 6 to 24 months. Serum 25(OH)D levels had no significant correlation with TSH $(\mathrm{r}=0.022, P=$ $0.236)$, FT3 $(\mathrm{r}=0.014, P=0.440)$ and FT4 $(\mathrm{r}=-0.059, P=0.056)$ levels. No significant difference in the levels of thyroid hormones was found between the different quartiles of 25 $(\mathrm{OH}) \mathrm{D}$ level. Vitamin D deficiency $[25(\mathrm{OH}) \mathrm{D}<50 \mathrm{nmol} / \mathrm{L}]$ was associated with hypothyroidism (adjusted odds ratio $=2.16,95 \%$ confidence interval: 1.18-3.94) but not with subclinical hypothyroidism, hyperthyroidism, and subclinical hyperthyroidism.

Conclusion: Vitamin D deficiency is slightly associated with hypothyroidism. No associations were found between serum 25(OH)D levels and thyroid-related measures (TSH, FT3, and FT4) in previously healthy children aged 6-24 months.

Keywords: thyroid stimulating hormone, free triiodothyronine, free thyroxine

\section{Introduction}

Thyroid diseases, including euthyroid goiter, hypothyroidism, and hyperthyroidism, are estimated to affect $1.4-6 \%$ children worldwide. ${ }^{1}$ Normal thyroid hormone levels play a key role in maintaining normal brain development, height, and growth velocity. Untreated overt thyroid diseases before the age of 3 years is well known to lead to a short stature, mental retardation, and brain damage. ${ }^{2,3}$

Testing of vitamin D levels has substantially increased in recent years, and emerging evidence suggests that vitamin $\mathrm{D}$ insufficiency is a common condition worldwide. ${ }^{4,5}$ Vitamin D insufficiency, defined as 25-hydroxyvitamin D [25(OH)D] 
level $<75 \mathrm{nmol} / \mathrm{L}$, is estimated to affect $40 \%$ of the population, ${ }^{6}$ and it might be a novel risk factor for some chronic diseases. Consequently, many studies have disclosed the possible role of vitamin D in non-skeletal clinical outcomes, including autoimmune diseases, infectious diseases, metabolic syndromes, and cardiovascular disorders. ${ }^{7,8}$ Furthermore, vitamin D plays an important role in immunomodulation, potentially affecting the thyroid gland through immune-mediated processes. ${ }^{9}$ Recent evidence has demonstrated that the distribution of thyroid stimulating hormone (TSH) level is influenced by $25(\mathrm{OH})$ D levels. A large population-based study reported that increased $25(\mathrm{OH}) \mathrm{D}$ levels were associated with decreased circulating TSH among younger individuals (mean age 29.2 years). ${ }^{10}$ Naghmeh et al suggest that a serum 25 $(\mathrm{OH}) \mathrm{D}$ level $>125 \mathrm{nmol} / \mathrm{L}$ is required for the maintenance of euthyroid functions. ${ }^{11}$ Nevertheless, the effect of 25 $(\mathrm{OH}) \mathrm{D}$ level on thyroid functions is still controversial. A population-based study using data collected by the National Health and Nutrition Examination Survey in the USA found that $25(\mathrm{OH}) \mathrm{D}$ levels were associated with neither thyroid functions nor thyroid antibody status among subjects aged 12-85 years. ${ }^{12}$

Few studies have focused on investigating the correlation between $25(\mathrm{OH}) \mathrm{D}$ levels and thyroid disorders in children. In one such study, the group of children diagnosed with Hashimoto's thyroiditis had a significantly higher prevalence of vitamin D deficiency than the control group. ${ }^{13}$ A similar study found a significant association between low vitamin D levels and autoimmune thyroiditis in Egyptian children; moreover, the study also reported that serum $25(\mathrm{OH}) \mathrm{D}$ levels were negatively associated with TSH and thyroid autoantibody levels. ${ }^{14}$

There is a scarcity of data on the effect of vitamin D status on thyroid function in children. Based on a large database of healthy children with detailed data on $25(\mathrm{OH})$ D status and thyroid hormone levels, we aimed to investigate the association between $25(\mathrm{OH}) \mathrm{D}$ status and thyroid function, and further, to assess the relationship between 25 $(\mathrm{OH}) \mathrm{D}$ levels and thyroid function parameters.

\section{Patients and Methods Study Design and Participants}

The data for the cross-sectional study were extracted from a hospital information system database, which was constructed to include all routine health check-up data of children to promote early childhood development at
Guangdong Women and Children's Hospital. In the present analysis, we included 6-24 month-old children with data of serum $25(\mathrm{OH}) \mathrm{D}, \mathrm{TSH}$, free triiodothyronine (FT3), and free thyroxine (FT4) levels from January 2015 to May 2017. Additionally, the following information was available: age, gender, and season of the testing. To ensure a relatively healthy study population, children with a history of illness (including clinical thyroid dysfunctions, skeletal diseases, genetic syndromes, and malabsorptive disorders) were excluded. After considering the inclusion and exclusion criteria, 2869 children aged 6-24 months were included in the final analysis.

\section{Ethics Statement}

Ethical approval was obtained from the Institutional Review Board of Guangdong Women and Children's Hospital, Guangzhou, China (No. 201,701,068). This study was conducted in accordance with the Declaration of Helsinki. The requirement for written informed consent was waived owing to the retrospective nature of the study. The privacy of the participants was preserved with anonymized data.

\section{Laboratory Assessments}

Serum 25(OH)D levels were measured by electrochemiluminescence immunoassay. The detailed laboratory procedures have been reported elsewhere. ${ }^{15}$ Serum $25(\mathrm{OH})$ $\mathrm{D}$ levels were divided into three categories: deficiency $(25(\mathrm{OH}) \mathrm{D}<50 \mathrm{nmol} / \mathrm{L})$, insufficiency $(50 \mathrm{nmol} / \mathrm{L} \leq 25$ $(\mathrm{OH}) \mathrm{D}<75 \mathrm{nmol} / \mathrm{L})$, and sufficiency $(25(\mathrm{OH}) \mathrm{D} \geq 75$ $\mathrm{nmol} / \mathrm{L}$ ) according to the guidelines released by the Endocrine Society, ${ }^{16}$ and TSH, FT3, and FT4 levels were measured by electrochemiluminescence immunoassay. The reference ranges for thyroid function parameters were as follows: TSH, 0.35-4.94 mIU/L; FT3, 3.69-7.68 pmol/L; and, FT4, 11.84-22.52 pmol/L. Thyroid dysfunctions were defined as: hyperthyroidism $(\mathrm{TSH}<0.35 \mathrm{mIU} / \mathrm{mL}, \mathrm{FT} 3>7.68 \mathrm{pmol} / \mathrm{L}$ and $\mathrm{FT} 4>$ $14.4 \mathrm{pmol} / \mathrm{L})$, subclinical hyperthyroidism $(\mathrm{TSH}<0.35$ $\mathrm{mIU} / \mathrm{mL}$, normal FT3 and FT4 levels), hypothyroidism $(\mathrm{TSH}>4.94 \mathrm{mIU} / \mathrm{mL}, \mathrm{FT} 3<3.69 \mathrm{pmol} / \mathrm{L}$ and FT4 $<$ $11.84 \mathrm{pmol} / \mathrm{L})$, and subclinical hypothyroidism $(\mathrm{TSH}>$ $4.94 \mathrm{mIU} / \mathrm{mL}$, normal FT3 and FT4 levels).

\section{Statistical Analysis}

The means and standard deviations were used to describe the continuous variables. Categorical variables were presented as frequencies and proportions (\%). The 
seasons of blood sample testing were categorized as follows: March to May, spring; June to August, summer; September to November, autumn; and, December to February, winter. For comparison of multiple groups, the ANOVA test was used for continuous variables, and the chi-square test was used for categorical variables. To reduce skewness and kurtosis, a Blom transformation was applied to TSH, FT3, and FT4, and 25 $(\mathrm{OH}) \mathrm{D}$ level values. Pearson correlation analyses were conducted to determine the associations between Blomtransformed TSH, FT3, and FT4, and 25(OH)D levels. Adjusted odds ratios (OR) and 95\% confidence intervals (CI) for the associations of vitamin D deficiency or insufficiency with thyroid dysfunctions were estimated using logistic regression models. $\mathrm{P}<0.05$ was considered as statistically significant. All statistical analyses were performed using the SPSS statistical software package (V20, IBM Statistics, Chicago, IL, USA).
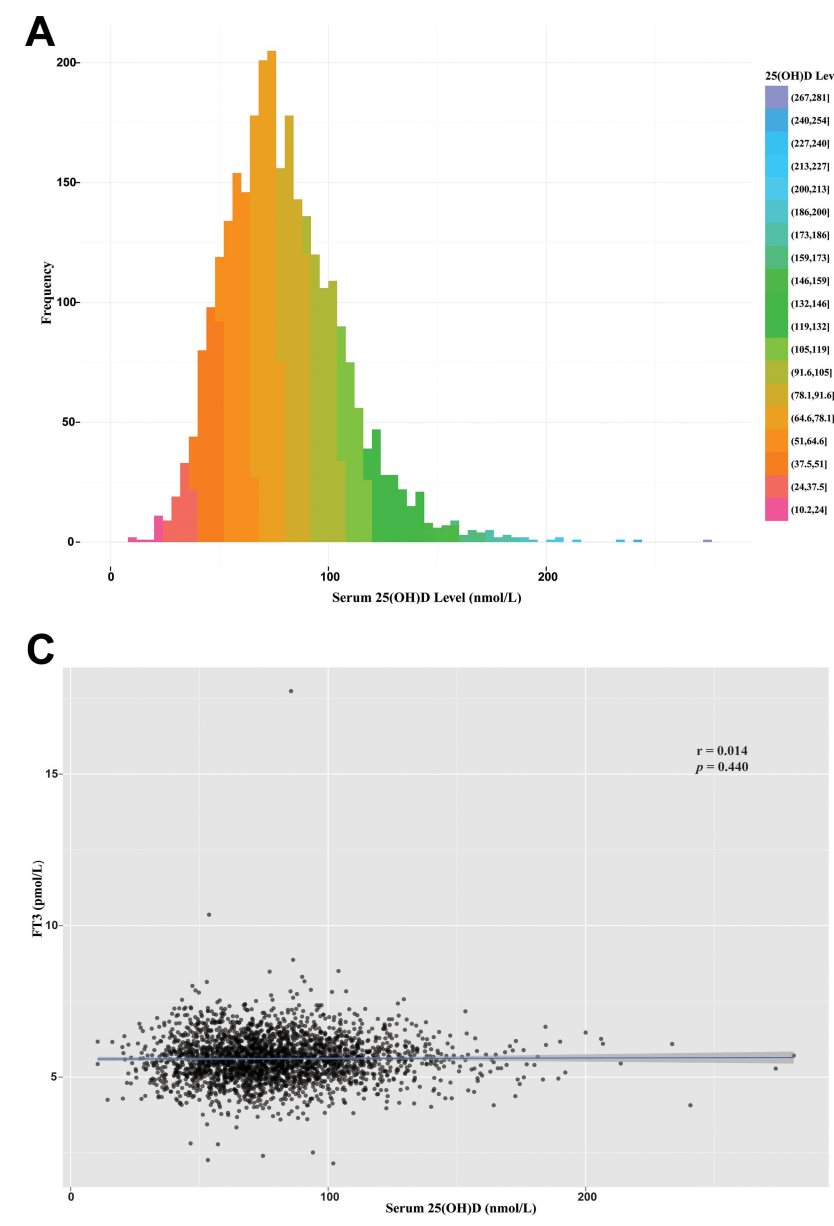

\section{Results}

The study population of 2869 children aged 6-24 months had a mean serum $25(\mathrm{OH}) \mathrm{D}$ level of $79.7 \pm 28.1 \mathrm{nmol} / \mathrm{L}$ (Figure 1A) and $12.5 \%$ vitamin D deficiency and 36.0\% insufficiency rates. The rate of vitamin D deficiency was lower in the group aged 6-12 months (8.6\%) than in the group aged 13-24 months (15.3\%). Of these, in the participants with no clinical symptoms, the rates of thyroid dysfunctions detected were as follows: $2.9 \%$, hypothyroidism; $4.2 \%$, subclinical hypothyroidism; $0.9 \%$, hyperthyroidism; and, $1.7 \%$ subclinical hyperthyroidism. The participants' characteristics are presented in Table 1.

Serum 25(OH)D levels had no significant correlation with TSH $(\mathrm{r}=0.022, P=0.236)$, FT3 $(\mathrm{r}=0.014$, $P=0.440)$, and FT4 $(\mathrm{r}=-0.059, P=0.056)$ levels (Figure 1B-D). On analyzing according to 25 $(\mathrm{OH}) \mathrm{D}-$ level quartiles (Q1: 10.5-60.2 $\mathrm{nmol} / \mathrm{L}$, Q2: 60.3-76 nmol/L, Q3: 76.1-95.3 nmol/L, and Q4: 95.3-280.8 $\mathrm{nmol} / \mathrm{L}$ ), the thyroid parameters (TSH,

B

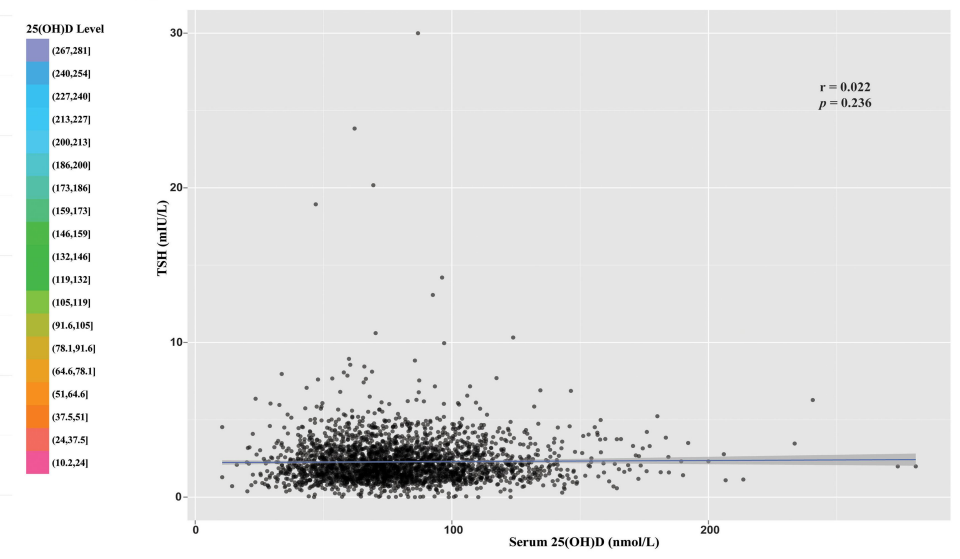

D

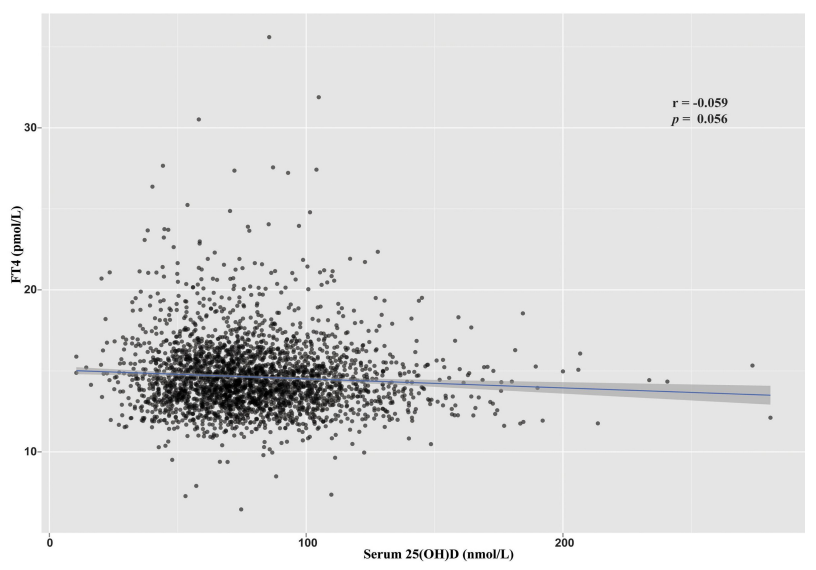

Figure I Serum 25-hydroxyvitamin $\mathrm{D}[25(\mathrm{OH}) \mathrm{D}]$ level distributions $(\mathbf{A})$ and correlations between thyroid stimulating hormone $(\mathbf{B})$, free triiodothyronine $(\mathbf{C})$, and free thyroxine (D), and serum 25(OH)D levels. 
Table I Participants' Characteristics by 25(OH)D Levels in Children Aged 6-24 Months

\begin{tabular}{|c|c|c|c|c|c|c|}
\hline Characteristics & $\begin{array}{l}\text { All Subjects }(n= \\
2869)\end{array}$ & $\begin{array}{l}25(\mathrm{OH}) \mathrm{D}<50 \\
\mathrm{nmol} / \mathrm{L} \\
(\mathrm{n}=358)\end{array}$ & $\begin{array}{l}50 \mathrm{nmol} / \mathrm{L} \leq 25(\mathrm{OH}) \mathrm{D}< \\
75 \mathrm{nmol} / \mathrm{L} \\
(\mathrm{n}=1033)\end{array}$ & $\begin{array}{l}25(\mathrm{OH}) \mathrm{D} \geq 75 \\
\mathrm{nmol} / \mathrm{L} \\
(\mathrm{n}=1478)\end{array}$ & $\begin{array}{l}\chi^{2} / F \\
\text { value }\end{array}$ & $\begin{array}{l}P \\
\text { value }\end{array}$ \\
\hline \multicolumn{7}{|l|}{ Sex, n (\%) } \\
\hline Male & $1482(5 \mid .7)$ & $169(11.4)$ & $538(36.3)$ & $775(52.3)$ & $3.273^{\mathrm{a}}$ & 0.195 \\
\hline Female & I $387(48.3)$ & $189(13.6)$ & $495(35.7)$ & $703(50.7)$ & & \\
\hline \multicolumn{7}{|l|}{ Age, n (\%) } \\
\hline 6-12 months & $121 \mid(42.2)$ & $104(8.6)$ & $360(29.7)$ & $747(6 \mid .7)$ & $90.412^{\mathrm{a}}$ & $<0.001$ \\
\hline 13-24 months & $1658(57.8)$ & $254(15.3)$ & $673(40.6)$ & $731(44.1)$ & & \\
\hline \multicolumn{7}{|l|}{ Season of testing, $n(\%)$} \\
\hline Spring & $1054(36.7)$ & $135(12.8)$ & $402(38.1)$ & $517(49.1)$ & $27.284^{\mathrm{a}}$ & $<0.001$ \\
\hline Summer & $609(21.2)$ & $51(8.4)$ & $211(34.6)$ & $347(57.0)$ & & \\
\hline Autumn & $657(22.9)$ & $110(16.7)$ & $215(32.7)$ & $332(50.5)$ & & \\
\hline Winter & $549(19.1)$ & $62(11.3)$ & $205(37.3)$ & $282(5 I .4)$ & & \\
\hline \multicolumn{7}{|l|}{ Thyroid parameters } \\
\hline TSH (mlU/mL) & $2.28 \pm 1.48$ & $2.26 \pm 1.54$ & $2.29 \pm 1.51$ & $2.28 \pm 1.45$ & $0.060^{\mathrm{b}}$ & 0.942 \\
\hline FT3 (pmol/L) & $5.61 \pm 0.75$ & $5.6 \pm 0.75$ & $5.58 \pm 0.74$ & $5.63 \pm 0.76$ & $1.393^{\mathrm{b}}$ & 0.248 \\
\hline FT4 (pmol/L) & $14.62 \pm 2.2$ & $14.9 \pm 2.55$ & $14.67 \pm 2.13$ & $14.53 \pm 2.15$ & $4.406^{\mathrm{b}}$ & 0.012 \\
\hline \multicolumn{7}{|l|}{ Thyroid dysfunction, n (\%) } \\
\hline Hypothyroidism & $84(2.9)$ & $17(20.2)$ & $31(36.9)$ & $36(42.9)$ & $17.714^{\mathrm{a}}$ & 0.023 \\
\hline Subclinical hypothyroidism & $|2|(4.2)$ & $14(11.6)$ & $45(37.2)$ & $62(51.2)$ & & \\
\hline Hyperthyroidism & $27(0.9)$ & I (3.7) & $10(37.0)$ & $16(59.3)$ & & \\
\hline Subclinical hyperthyroidism & $48(1.7)$ & $13(27.1)$ & $12(25.0)$ & $23(47.9)$ & & \\
\hline
\end{tabular}

Notes: a Differences between groups are tested with the chi-square test. ${ }^{b}$ Differences between groups are tested with the ANOVA one-way test. Abbreviations: 25(OH)D, serum 25-hydroxyvitamin D; FT3, free triiodothyronine; FT4, free thyroxine; TSH, thyroid stimulating hormone.

FT3, and FT4 levels) were also not significantly different between 25(OH)D level quartiles (all $\mathrm{P}>0.05$ ) (Figure 2).

Table 2 shows the logistic regression analysis, which assessed the association between vitamin D deficiency or insufficiency and thyroid dysfunctions. Vitamin D deficiency $[25(\mathrm{OH}) \mathrm{D}<50 \mathrm{nmol} / \mathrm{L}]$ was associated with an increased risk of hypothyroidism (adjusted OR $=2.16$, 95\% CI: $1.18-3.94$ ) after adjusting for age, sex, and season of testing, but not with subclinical hypothyroidism, hyperthyroidism, and subclinical hyperthyroidism. Further, the hypothyroidism subgroup was analyzed to evaluate the associations between serum 25(OH)D levels and thyroid-related measures. Serum 25(OH)D levels did not correlate with TSH $(\mathrm{r}=0.042, P=$ 0.704), FT3 ( $\mathrm{r}=0.035, P=0.751)$, and FT4 ( $\mathrm{r}=$ $0.089, P=0.421)$ levels. On analyzing the probable interactions between 25(OH)D levels and seasons and their influence on thyroid levels, no significant differences in thyroid hormone levels were found between the different quartiles of vitamin D levels (Table 3).

\section{Discussion}

$25(\mathrm{OH}) \mathrm{D}$ is the principal stored form of vitamin $\mathrm{D}$. The measurement of serum 25(OH)D levels is considered to be the best diagnostic test to assess the vitamin D status. ${ }^{17,18}$ Although the definition of vitamin D deficiency has remained controversial, serum $25(\mathrm{OH}) \mathrm{D}$ concentration $<50 \mathrm{nmol} / \mathrm{L}$ is usually defined as deficiency by most authors. ${ }^{16}$ According to the definition used in this crosssectional study of children aged 6-24 months, our findings are in agreement with the findings of other reports that show a high prevalence of vitamin D deficiency and insufficiency. ${ }^{6}$

Of the children without overt thyroid diseases, $2.9 \%$ were detected with hypothyroidism. Statistically, a significant association was found between vitamin D deficiency and the risk of hypothyroidism. Our results indicate that vitamin D might also have an immunomodulating effect on thyroid functions in the pediatric population. However, no significant associations were observed for subclinical hypothyroidism, hyperthyroidism, and subclinical hyperthyroidism. The underlying mechanism of the link 

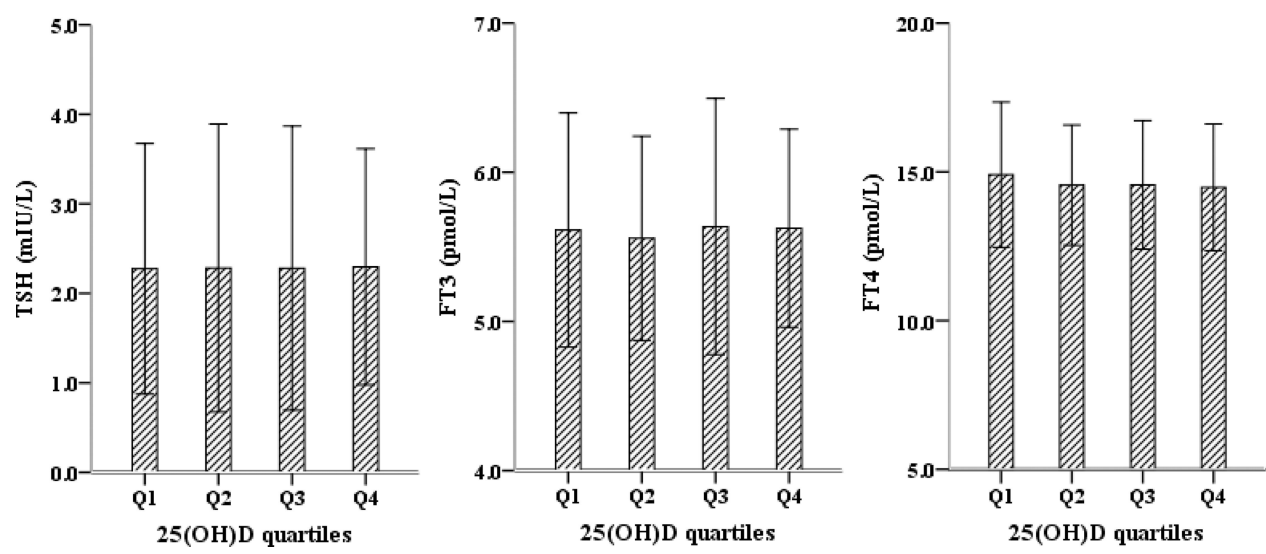

Figure 2 Thyroid hormones with serum 25-hydroxyvitamin $D[25(\mathrm{OH}) \mathrm{D}]$ quartiles. Thyroid stimulating hormone, free triiodothyronine, and free thyroxine did not significantly differ with $25(\mathrm{OH}) \mathrm{D}$ quartiles in children aged 6-24 months.

between vitamin $\mathrm{D}$ and autoimmunity is not fully understood; it might be related to its anti-inflammatory and immunomodulatory functions. ${ }^{19}$ Several studies have analyzed the supposed associations between vitamin D levels and Hashimoto's thyroiditis, autoimmune thyroiditis, and Graves' disease in adult subjects, ${ }^{20-23}$ with inconclusive results. In most of these studies, patients with overt thyroid diseases had lower 25(OH)D levels than normal or control subjects. Furthermore, no strong association was found between vitamin $\mathrm{D}$ status and abnormal thyroid functions in large population-based studies. ${ }^{10,24}$ The results of the present study, based on an early-childhood population, found that vitamin $\mathrm{D}$ deficiency was associated with an increased risk of hypothyroidism, after adjusting for age, sex, and season of testing. However, no associations were found between serum 25(OH)D levels and thyroid-related measures. The conflicting results may stem from cutoff values for hypothyroidism or vitamin $\mathrm{D}$ deficiency. Moreover, it implies that there may not be a linear relationship between serum 25(OH)D levels and thyroidrelated measures (TSH, FT3, and FT4).

Some studies have found that serum $25(\mathrm{OH}) \mathrm{D}$ concentrations and thyroid hormone levels may be affected by seasonal variability. ${ }^{25,26}$ Although the difference between FT3 and 25(OH)D quartiles was significant in the autumn subgroup $(P=0.037)$, the actual differences between FT3 levels were very small and the overall results tended to accentuate no difference. For this reason, we considered that this phenomenon is probably a chance finding and should not be regarded as conclusive. Inconsistent conclusions in different studies might be related to the study design, region, heterogeneity of the study population, sample collection seasons, thyroid hormones and vitamin D level detection methods, and evaluation criteria. More powerful research in the future is needed.

Our study adds to the lack of research between vitamin D status and thyroid functions in the early-childhood population. However, our results should be interpreted in the light of possible limitations. The effects of serum 25 $(\mathrm{OH}) \mathrm{D}$ levels on thyroid functions would be confounded by other factors. The data for the present study were extracted from the hospital information registration system. The feeding methods, vitamin D supplements, outdoor activities, and other confounding factors, which affect vitamin D levels, were not available in the registers. Therefore, the associations between serum 25(OH)D

Table 2 Association Between Vitamin D Deficiency, Insufficiency, and Thyroid Dysfunction

\begin{tabular}{|c|c|c|c|c|}
\hline Thyroid Dysfunction & $\begin{array}{l}\text { Adjusted OR }(95 \% \mathrm{Cl}) 25(\mathrm{OH}) \mathrm{D}<50 \\
\mathrm{nmol} / \mathrm{L} \text { vs } 25(\mathrm{OH}) \mathrm{D} \geq 75 \mathrm{nmol} / \mathrm{L}\end{array}$ & $\begin{array}{l}P \\
\text { value }\end{array}$ & $\begin{array}{l}\text { Adjusted OR }(95 \% \mathrm{Cl}) 25(\mathrm{OH}) \mathrm{D} 50-75 \\
\mathrm{nmol} / \mathrm{L} \text { vs } 25(\mathrm{OH}) \mathrm{D} \geq 75 \mathrm{nmol} / \mathrm{L}\end{array}$ & $\begin{array}{l}P \\
\text { value }\end{array}$ \\
\hline Hypothyroidism & $2.16(1.18,3.94)$ & 0.012 & I.3I $(0.80,2.15)$ & 0.280 \\
\hline Subclinical hypothyroidism & $\mathrm{I} .0 \mathrm{I}(0.55, \mathrm{I} .83)$ & 0.991 & $1.13(0.76,1.69)$ & 0.536 \\
\hline Hyperthyroidism & $0.26(0.04,2.02)$ & 0.264 & $0.96(0.43,2.16)$ & 0.931 \\
\hline Subclinical hyperthyroidism & I.54 $(0.86,2.77)$ & 0.150 & $0.76(0.38,1.55)$ & 0.455 \\
\hline
\end{tabular}

Notes: Adjusted for age, sex, and season of testing.

Abbreviations: $25(\mathrm{OH}) \mathrm{D}$, serum 25 -hydroxyvitamin $\mathrm{D}$; OR, odds ratio; $\mathrm{Cl}$, confidence interval. 
Table 3 Comparison of Different Thyroid Parameters with 25(OH)D Quartiles and Seasons

\begin{tabular}{|c|c|c|c|c|c|c|}
\hline \multirow[t]{2}{*}{ Thyroid Parameters } & \multicolumn{4}{|c|}{ 25(OH)D Quartiles } & \multirow[t]{2}{*}{$F$ value } & \multirow[t]{2}{*}{$P$ value } \\
\hline & QI & Q2 & Q3 & Q4 & & \\
\hline \multicolumn{7}{|l|}{ Spring } \\
\hline TSH (mlU/mL) & $2.40 \pm 1.41$ & $2.27 \pm 1.83$ & $2.46 \pm 2.2$ & $2.37 \pm 1.35$ & 0.512 & 0.674 \\
\hline FT3 (pmol/L) & $5.70 \pm 0.64$ & $5.63 \pm 0.55$ & $5.74 \pm 0.95$ & $5.73 \pm 0.60$ & 1.101 & 0.348 \\
\hline FT4 (pmol/L) & $14.99 \pm 2.44$ & $14.45 \pm 2.15$ & $|4.86 \pm 2.6|$ & $14.72 \pm 2.3$ & 2.269 & 0.079 \\
\hline \multicolumn{7}{|l|}{ Summer } \\
\hline TSH (mlU/mL) & $2.32 \pm 1.06$ & $2.38 \pm 1.92$ & $2.41 \pm 2.44$ & $2.32 \pm 1.20$ & 0.079 & 0.971 \\
\hline FT3 (pmol/L) & $5.5 \mathrm{I} \pm 0.63$ & $5.59 \pm 0.68$ & $5.51 \pm 0.66$ & $5.63 \pm 0.55$ & 1.529 & 0.206 \\
\hline FT4 (pmol/L) & $14.56 \pm 1.77$ & $14.37 \pm 1.89$ & $13.95 \pm 1.53$ & $14.37 \pm 1.80$ & 3.261 & 0.021 \\
\hline \multicolumn{7}{|l|}{ Autumn } \\
\hline TSH (mlU/mL) & $2.23 \pm 1.69$ & $2.28 \pm 2.27$ & $2.33 \pm 1.06$ & $2.25 \pm 1.49$ & 0.100 & 0.960 \\
\hline FT3 (pmol/L) & $5.55 \pm 0.79$ & $5.62 \pm 0.68$ & $5.76 \pm 0.73$ & $5.71 \pm 0.68$ & $2.84 I$ & 0.037 \\
\hline FT4 (pmol/L) & $14.58 \pm 2.12$ & $14.58 \pm 2.16$ & $14.21 \pm 1.70$ & $14.3 \pm 2.09$ & 1.429 & 0.233 \\
\hline \multicolumn{7}{|l|}{ Winter } \\
\hline TSH (mlU/mL) & $2.46 \pm 1.50$ & $2.41 \pm 1.33$ & $2.18 \pm 1.14$ & $2.23 \pm 1.13$ & 1.574 & 0.195 \\
\hline FT3 (pmol/L) & $5.55 \pm 0.75$ & $5.54 \pm 0.69$ & $5.62 \pm 1.28$ & $5.56 \pm 0.73$ & 0.222 & 0.881 \\
\hline FT4 (pmol/L) & $14.99 \pm 2.85$ & $14.74 \pm 2.16$ & $14.84 \pm 2.84$ & $14.62 \pm 2.34$ & 0.492 & 0.688 \\
\hline
\end{tabular}

Notes: 25(OH)D levels quartiles (QI: 10.5-60.2 nmol/L, Q2: 60.3-76 nmol/L, Q3: 76.I-95.3 nmol/L, Q4: 95.3-280.8 nmol/L).

Abbreviations: 25(OH)D, serum 25-hydroxyvitamin D; FT3, free triiodothyronine; FT4, free thyroxine; TSH, thyroid stimulating hormone.

levels and thyroid functions might be underestimated. Moreover, there were a lack of clinical and biochemical data that would have allowed better sub-classification, such as TSH receptor antibody, anti-thyroglobulin, and anti-thyroid peroxidase antibody levels. Finally, our study is a single-center and cross-sectional study, which cannot be inferred for causality. The sample is not from the random general population, and the representativeness of the participants might be affected by selection bias.

\section{Conclusion}

A vitamin D deficiency is associated with hypothyroidism. No significant relationships were observed between 25 $(\mathrm{OH}) \mathrm{D}$ levels and TSH, FT3, and FT4 in children aged 6-24 months. Further studies are needed to support the associations and to determine whether vitamin D deficiency is a risk factor for the progression of thyroid disorders in early childhood.

\section{Abbreviations}

25(OH)D, serum 25-hydroxyvitamin D; FT3, free triiodothyronine; FT4, free thyroxine; TSH, thyroid stimulating hormone; OR, odds ratio; $\mathrm{CI}$, confidence interval.

\section{Funding}

This work was supported in part by the Medical Scientific Research Foundations of Guangdong Province, China [A2018255].

\section{Disclosure}

The authors report no conflicts of interest in this work.

\section{References}

1. Pasala P, Francis GL. Autoimmune thyroid diseases in children. Exp Rev Endocrinol Metab. 2017;12(2):129-142. doi:10.1080/17446651. 2017.1300525

2. Salerno M, Improda N, Capalbo D. Management of endocrine disease subclinical hypothyroidism in children. Eur J Endocrinol. 2020;183 (2):R13-R28. doi:10.1530/EJE-20-0051

3. Lain SJ, Bentley JP, Wiley V, et al. Association between borderline neonatal thyroid-stimulating hormone concentrations and educational and developmental outcomes: a population-based record-linkage study. Lancet Diabetes Endocrinol. 2016;4(9):756-765. doi:10.1016/S22138587(16)30122-X

4. Crowe FL, Jolly K, MacArthur C, et al. Trends in the incidence of testing for vitamin D deficiency in primary care in the UK: a retrospective analysis of the health improvement network (THIN), 2005-2015. BMJ Open. 2019;9(6):e028355. doi:10.1136/bmjopen-201 8-028355

5. Li H, Huang T, Xiao P, et al. Widespread vitamin D deficiency and its sex-specific association with adiposity in Chinese children and adolescents. Nutrition. 2019;71:110646. doi:10.1016/j.nut.2019.11 0646 
6. Amrein K, Scherk1 M, Hoffmann M, et al. Vitamin D deficiency 2.0: an update on the current status worldwide. Eur J Clin Nutr. 2020;20:1-16.

7. Plum LA, DeLuca HF, Vitamin D. Disease and therapeutic opportunities. Nat Rev Drug Discov. 2010;9(12):941-955. doi:10.1038/ $\operatorname{nrd} 3318$

8. Makariou S, Liberopoulos EN, Elisaf M, et al. Novel roles of vitamin D in disease: what is new in 2011? Eur J Intern Med. 2011;22 (4):355-362. doi:10.1016/j.ejim.2011.04.012

9. D'Aurizio F, Villalta D, Metus P, et al. Is vitamin D a player or not in the pathophysiology of autoimmune thyroid diseases? Autoimmun Rev. 2015;14(5):363-369. doi:10.1016/j.autrev.2014.10.008

10. Chailurkit LO, Aekplakorn W, Ongphiphadhanakul B. High vitamin $\mathrm{D}$ status in younger individuals is associated with low circulating thyrotropin. Thyroid. 2013;23(1):25-30. doi:10.1089/thy.2012.0001

11. Mirhosseini N, Brunel L, Muscogiuri G, et al. Physiological serum 25hydroxyvitamin D concentrations are associated with improved thyroid function-observations from a community-based program. Endocrine. 2017;58(3):563-573. doi:10.1007/s12020-017-1450-y

12. Zhou P, Cai J, Markowitz M. Absence of a relationship between thyroid hormones and vitamin D levels. J Pediatr Endocrinol Metab. 2016;29(6):703-707. doi:10.1515/jpem-2015-0210

13. Camurdan OM, Doger E, Bideci A, et al. Vitamin D status in children with Hashimoto thyroiditis. J Pediatr Endocrinol Metab. 2012;25(56):467-470. doi:10.1515/jpem-2012-0021

14. Metwalley KA, Farghaly HS, Sherief T, et al. Vitamin D status in children and adolescents with autoimmune thyroiditis. J Endocrinol Invest. 2016;39(7):793-797. doi:10.1007/s40618-016-0432-x

15. Guo Y, Ke HJ, Liu Y, et al. Prevalence of vitamin D insufficiency among children in southern china: a cross-sectional survey. Medicine. 2018;97(25):e11030. doi:10.1097/MD.0000000000011030

16. Holick MF, Binkley NC, Bischoff-Ferrari HA, et al. Evaluation, treatment, and prevention of vitamin D deficiency: an endocrine society clinical practice guideline. J Clin Endocrinol Metab. 2011;96(7):1911-1930. doi:10.1210/jc.2011-0385
17. Prietl B, Treiber G, Pieber TR, et al. Vitamin D and immune function. Nutrients. 2013;5(7):2502-2521. doi:10.3390/nu5072502

18. Kim D. The role of vitamin D in thyroid diseases. Int J Mol Sci. 2017;18(9):1949. doi:10.3390/ijms 18091949

19. Agmon-Levin N, Theodor E, Segal RM, et al. Vitamin D in systemic and organ-specific autoimmune diseases. Clin Rev Allergy Immunol. 2013;45(2):256-266. doi:10.1007/s12016-012-8342-y

20. Kivity S, Agmon-Levin N, Zisappl M, et al. Vitamin D and autoimmune thyroid diseases. Cell Mol Immunol. 2011;8:243-247.

21. Mansournia N, Mansournia MA, Saeedi S, et al. The association between serum 25OHD levels and hypothyroid Hashimoto's thyroiditis. J Endocrinol Invest. 2014;37(5):473-476. doi:10.1007/s40618014-0064-y

22. Kim D. Low vitamin D status is associated with hypothyroid Hashimoto's thyroiditis. Hormones. 2016;15(3):385-393. doi:10.14 310/horm.2002.1681

23. Faghfouri A, Bagheri M, Mehdizadeh A, et al. Vitamin D level and vitamin D receptor gene polymorphisms in Iranian Azeri Turkish patients with autoimmune thyroid diseases. Acta Medica Iran. 2018;56:508-515.

24. Choi YM, Kim WG, Kim TY, et al. Low levels of serum vitamin D3 are associated with autoimmune thyroid disease in pre-menopausal women. Thyroid. 2014;24(4):655-661. doi:10.1089/thy.20 13.0460

25. Barchetta I, Baroni MG, Leonetti F, et al. TSH levels are associated with vitamin D status and seasonality in an adult population of euthyroid adults. Clin Exp Med. 2015;15(3):389-396. doi:10.1007/ s10238-014-0290-9

26. Nanri A, Foo LH, Nakamura K, et al. Serum 25-hydroxyvitamin d concentrations and season-specific correlates in Japanese adults. $J$ Epidemiol. 2011;21(5):346-353. doi:10.2188/jea.JE20100161
Risk Management and Healthcare Policy

\section{Publish your work in this journal}

Risk Management and Healthcare Policy is an international, peerreviewed, open access journal focusing on all aspects of public health, policy, and preventative measures to promote good health and improve morbidity and mortality in the population. The journal welcomes submitted papers covering original research, basic science, clinical \& epidemiological studies, reviews and evaluations, guidelines, expert opinion and commentary, case reports and extended reports. The manuscript management system is completely online and includes a very quick and fair peer-review system, which is all easy to use. Visit http://www.dovepress.com/testimonials.php to read real quotes from published authors. 